\title{
Minimizing the Risk of Inappropriately Administering Thrombolytic Therapy (Thrombolysis and Angioplasty in Myocardial Infarction [TAMI] Study Group)
}

\author{
Gregory D. Chapman, MD, E. Magnus Ohman, MB, Eric J. Topol, MD, \\ Richard J. Candela, MD, Dean J. Kereiakes, MD, Joseph Samaha, MD, Eric Berrios, RN, \\ Karen S. Pieper, MS, Sharon Y. Young, MS, and Robert M. Califf, MD
}

\begin{abstract}
Despite the proven benefits of thrombolytic therapy in acute myocardial infarction, concern for its complications, especially in patients misdiagnosed with myocardial infarction, has led to hesitancy in its use. Historical, clinical and electrocardiographic criteria were developed for enrolling patients with suspected acute myocardial infarction into thrombolytic trials by noncardiovascular specialists. The incidence of misdiagnosis of myocardial infarction and the clinical outcomes when these criteria were used were evaluated for 1,387 consecutive patients given thrombolytic therapy.
\end{abstract} Twenty-five community hospitals and 7 interventional centers were the sites of enrollment. Most patients (63\%) were enrolled from community hospitals. Criteria for thrombolytic therapy included: symptoms of acute myocardial infarction $<6$ hours but $>20$ minutes, and not relieved by nitroglycerin; and ST-segment elevation $\geq 1 \mathrm{~mm}$ in 2 contiguous leads or ST-segment depression of posterior myocardial infarction. Exclusion criteria reflecting increased risk of bleeding were used. A final diagnosis of myocardial infarction was based on creatinine kinase-MB, electrocardiographic and ventriculographic evaluation. Acute myocardial infaretion was misdiagnosed in 20 patients (1.4\%; 95\% confidence interval $0.8-2.0 \%$ ). These patients were demographically similar to those with acute myocardial infarction. All misdiagnosed patients survived; no significant adverse events occurred. Thus, in several clinical settings, a simple algorithm with specific criteria was used for diagnosing acute myocardial infarction and administering thrombolytic therapy. The inclusion criteria used in this study led to a low rate of misdiagnosis.

(Am J Cardiol 1993;71:783-787)
$\mathrm{T}$ Thrombolytic therapy is standard care in treating acute myocardial infarction in appropriately selected patients. ${ }^{1}$ Well-controlled studies have proved its role in restoring vessel patency, improving left ventricular function and decreasing mortality. ${ }^{2-7}$ Despite these benefits, apprehension for its complications may limit its use. Infrequent but major bleeding complications ${ }^{8}$ raise concern, especially in patients with a mistaken diagnosis of acute myocardial infarction. Reports of the disastrous consequences of thrombolytic therapy to patients with aortic dissection or hemorrhagic pericarditis reinforce this issue., ${ }^{89}$

Given the high incidence and multiple etiologies of chest pain, and the need to administer thrombolytics early in the course of infarction, a mistaken diagnosis with inappropriate treatment could be extremely frequent. Misdiagnosis rates for acute myocardial infarction as great as $41 \%$ have been reported when electrocardiographic criteria are not used. ${ }^{10}$ However, elecirocardiographic criteria alone may be insufficient. Lee et a ${ }^{11}$ found that approximately $25 \%$ of patients who presented with acute chest pain and ST elevation did not have myocardial infarction.

In addition, most patients with suspected acute infarction are evaluated by primary care physicians without specialized training in cardiovascular medicine. The primary care physician may be less comfortable than a cardiologist in making the diagnosis and initiating thrombolytic therapy. Therefore, specific criteria for patient enrollment in community hospitals were developed by the Thrombolysis and Angioplasty in Myocardial Infarction (TAMI) study group (see later). These criteria were used in several different clinical settings, primarily by physicians who are not cardiovascular specialists. The purpose of this study was to evaluate the incidence and outcomes of misdiagnosis of acute myocardial infarction for patients given thrombolytic therapy in our series of 5 multicenter trials.

\section{METHODS}

Criteria for patient selection: Patients enrolled in the TAMI-1, 2 and 3, Intravenous Urokinase and TAMI5 thrombolytic trials were evaluated for confirmation of myocardial infarction. The protocols for these studies, which were approved by institutional review boards at each facility and required informed consent for patient participation, were published previously. ${ }^{12-16}$ Patients were considered for inclusion if they had symptoms of 


\begin{tabular}{|c|c|c|}
\hline & $\begin{array}{c}\text { AMI } \\
\langle n=1,367)\end{array}$ & $\begin{array}{l}\text { No AMI } \\
(n=20)\end{array}$ \\
\hline Age (year) & $56.9 \pm 10.2$ & $51.6 \pm 10.6$ \\
\hline 25th, 50th, 75th percentiles & $50,58,65$ & $42,51,59$ \\
\hline Men & $1,080(79 \%)$ & $14(70 \%)$ \\
\hline Systemic hypertension ${ }^{\star}$ & $588(43 \%)$ & $2(10 \%)$ \\
\hline Hyperlipidemia & $260(19 \%)$ & $4(20 \%)$ \\
\hline $\begin{array}{l}\text { Family } \mathrm{Hx} \text { of cardiovascular } \\
\text { disease }\end{array}$ & $725(53 \%)$ & $10(50 \%)$ \\
\hline Hx of smoking & $848(62 \%)$ & $12(60 \%)$ \\
\hline Diabetes & $219(16 \%)$ & $1(5 \%)$ \\
\hline Previous AMI & $178(13 \%)$ & $3(15 \%)$ \\
\hline Peripheral vascular disease & $68(5 \%)$ & 0 \\
\hline Heart rate (beats/min) & $78 \pm 18$ & $82 \pm 15$ \\
\hline 25th, 50th, 75th percentiles & $64,76,88$ & $71,79,95$ \\
\hline Systolic BP (mm Hg) & $132 \pm 24$ & $140 \pm 26$ \\
\hline 25th, 50th, 75 th percentiles & $114,130,148$ & $122,130,161$ \\
\hline Diastolic BP (mm Hg) & $82 \pm 17$ & $88 \pm 21$ \\
\hline 25th, 50th. 75th percentiles & $70,81,92$ & $77,84,98$ \\
\hline Rales & $259(19 \%)$ & $2(10 \%)$ \\
\hline$S_{3}$ gallop & $41(3 \%)$ & $1(5 \%)$ \\
\hline $\begin{array}{l}\text { Duration of chest pain before } \\
\text { thrombolytic Rx (min) }\end{array}$ & $181 \pm 87$ & $191 \pm 65$ \\
\hline 25th, 50th, 75th percentiles & $130,174,223$ & $129,213,244$ \\
\hline Peak CK (IU/L) & $1,943 \pm 2,255$ & $80.7 \pm 50.8$ \\
\hline 25th, 50 th, 75 th percentiles & $685,1,518,2,500$ & $47,62,103$ \\
\hline Peak CK-MB (IU/L) & $243 \pm 523$ & $4.8 \pm 3.5$ \\
\hline 25th, 50th, 75th percentiles & $49,108,234$ & $0.9,5.7,7.2$ \\
\hline \multicolumn{3}{|c|}{ 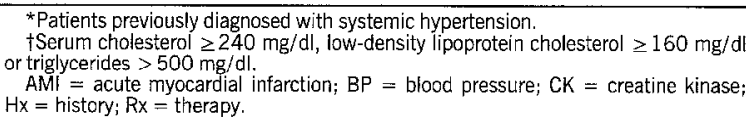 } \\
\hline
\end{tabular}

acute myocardial infarction for $<6$ hours but $>20$ minutes after onset. Patients who had prompt relief of symptoms with sublingual nitroglycerin were excluded. Electrocardiographic criteria were the presence of ST-segment elevation $\geq 1 \mathrm{~mm}$ in 2 contiguous leads or ST depression consistent with posterior infarction, in the absence of previous Q-wave infarction in the same infarct-related artery distribution. Patients aged $>75$ years, and those with a recent history of cerebrovascular disease, surgery, trauma, bleeding or coronary artery bypass grafting were excluded. Patients with significant hypertension $(>180 \mathrm{~mm} \mathrm{Hg}$ systolic or $>110 \mathrm{~mm} \mathrm{Hg}$ diastolic) or hypotension $(<80 \mathrm{~mm} \mathrm{Hg}$ systolic not responsive to fluid resuscitation) were also excluded. These specific criteria were used in 25 community hospitals and 7 interventional centers to enroll 1,387 patients; a complete listing of these hospitals was presented previously. 12

Determination of myocardial infarction: The attending cardiologist at each interventional center determined the final diagnosis for each patient based on creatinine kinase $(\mathrm{CK})-\mathrm{MB}$, electrocardiographic and ventriculographic evaluation in the setting of a compatible clinical event. Values for significant CK-MB elevation that were standard for each center were used and recordcd prospectively. The entry electrocardiogram was sent to the ECG Coordinating Center at Duke University Medical Center for analysis. Angiographic data were used where appropriate (e.g., unstable angina was diagnosed if significant coronary artery stenosis was noted and if no increase in CK-MB was detected).
Identification of patients misdiagnosed with myocardial infarction: Patients were identified in a prospective fashion by the diagnosis given during their hospitalization. In addition, the records for any patient with a coronary angiogram showing an infarct-related artery stenosis $<75 \%$ were reviewed for misdiagnosis of acute infarction.

Angiographic interpretation: All coronary angiograms were reviewed by the clinical staff at each institution in conjunction with the clinical diagnosis. Each coronary angiogram was then forwarded and independently evaluated at the University of Michigan Core Angiographic Laboratory. Left ventricular ejection fraction and the degree of coronary artery stenosis were assessed at the core laboratory as previously described. ${ }^{12,17,18}$ The core laboratory values were used for data review and analysis.

Determination of clinical outcomes: The major outcomes assessed in this study were death, nonhemorrhagic stroke, intracranial bleed, blood loss (needing transfusion of $\geq 2$ units of packed red blood cells), sustained hypotension and vascular repair of a catheterization site. Patients were carefully monitored throughout hospitalization. Multiple data itcms were collected prospectively by research nurses during the patients' clinical courses. The findings were forwarded to the Biostatistical Coordinating Center at Duke University Medical Center for data entry and quality assurance. All major outcomes were checked against the medical record. In addition, any documentation of the use of cocaine or alcohol, the occurrence of cardiac tamponade, or any other complication related to receiving thrombolytic therapy in the misdiagnosed group was assessed by reviewing medical records retrospectively.

Data analysis: Data are expressed as mean $\pm 1 \mathrm{SD}$, and as 25th, 50th and 75th percentiles for each group. A binomial distribution of dichotomous events was assumed for determining confidence intervals. ${ }^{19} \mathrm{~A}$ chisquare test was used to compare misdiagnosis rates between referral centers and community hospitals.

\section{RESULTS}

Percentage of study group misdiagnosed with acute myocardial infarction: Of 1,387 patients enrolled, 20 (1.4\%; 95\% confidence interval $0.82 .0 \%$ ) had no evolutionary evidence of acute myocardial infarction despite entry in the trial. Nonischemic chest pain syndromes in conjunction with early repolarization were observed in 4 patients; 1 with probable esophageal spasm presented with inferior ST elevation. Pericarditis $(\mathrm{n}=3)$, vasospasm $(\mathrm{n}=3)$, hypertensive cardiomyopathy $(\mathrm{n}=1)$ and unstable angina $(\mathrm{n}=8)$ were the diagnoses for 15 patients. The rates of misdiagnosis for the 5 trials were as follows: $1 \%$ (4 of 386) for TAMI-1, 1.4\% (1 of 147) for TAMI-2, 1.7\% (3 of 175) for TAMI-3, $2.9 \%$ ( 3 of 102) for the Intravenous Urokinase trial, and $1.4 \%$ ( 8 of 577 ) for TAMI-5. Community hospitals enrolled $63 \%$ of patients. Fifteen misdiagnosed patients were in this subgroup, resulting in a misdiagnosis rate for community hospitals of $1.7 \%$ (15 of 874 ). The remaining 5 misdiagnosed patients were initially evaluated in 1 of 7 tertiary hospitals, resulting in a misdiagno- 
sis rate for referral centers of $1 \%$ ( 5 of 513). The slightly greater misdiagnosis rate for community hospitals was not statistically significant $(\mathrm{p}=0.26)$.

Characteristics of patients with myocardial infarction versus misdiagnosed patients: Table I shows historical, clinical and cardiac enzyme data for the study group. The misdiagnosed group tended to be younger and had a lower incidence of history of hypertension; however, there were no differences for cardiovascular disease risk factors. Likewise, no difference was detected between the groups at presentation for heart rate, blood pressure, presence of rales or $S_{3}$ gallop, or in the
FIGURE 1. Top, entry electrocardiogram from patient with no coronary artery disease at catheterization, with final diagnosis of coronary vasospasm. Middle, entry electrocardiogram from pa tient with final diagnosis of left ventricular hypertrophy. Bottom, entry electrocardiogram from patient with no coronary artery disease at catheterization, with final diagnosis of benign ST eleva tion/early repolarization.

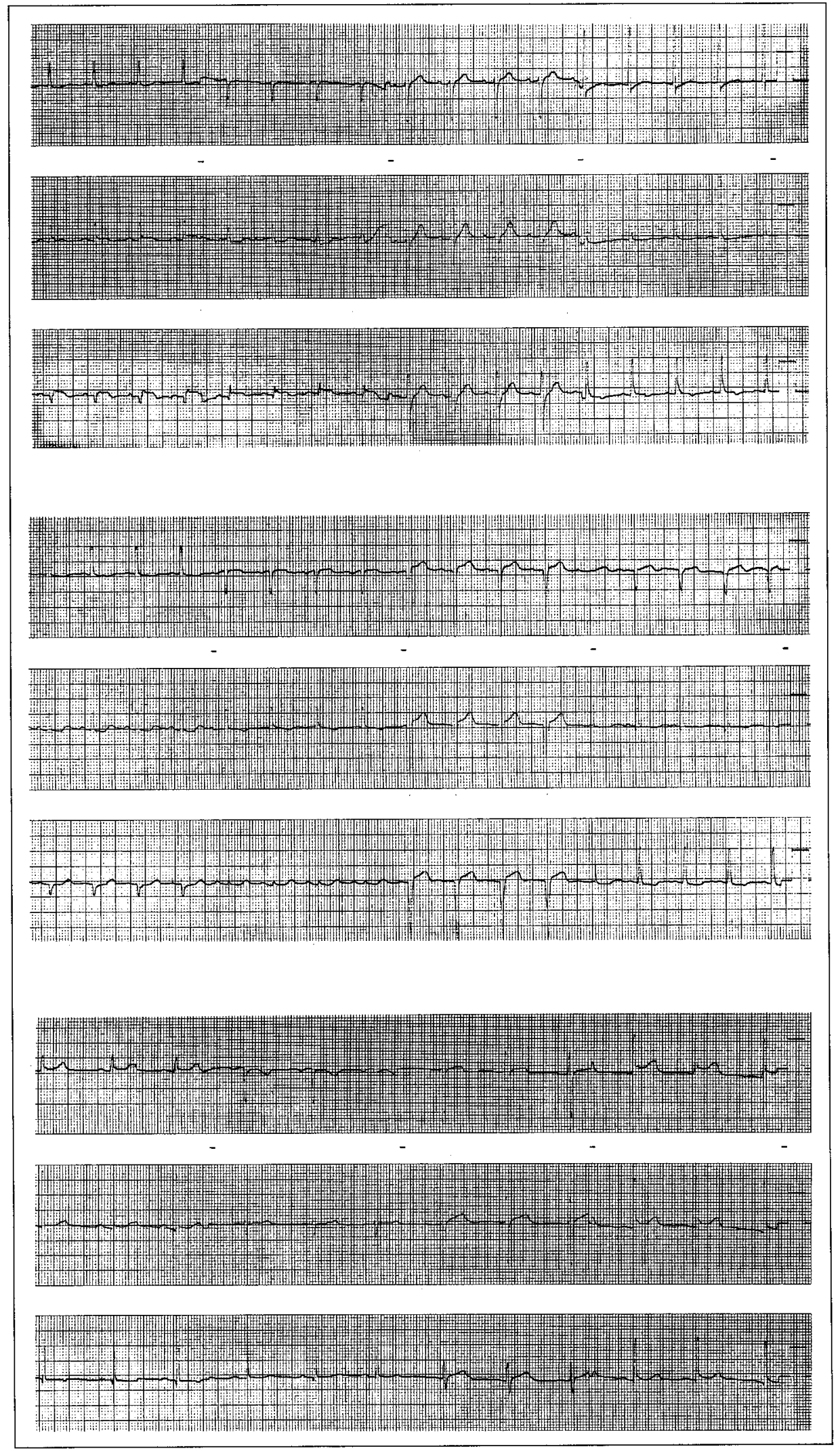


duration of chest pain before receiving thrombolytic therapy.

Figure 1 shows electrocardiograms from patients given thrombolytic therapy and subsequently diagnosed with coronary vasospasm, pericarditis and early repolarization. On review of the 20 entry electrocardiograms for the misdiagnosed group, $11(55 \%)$ did not fulfill the electrocardiographic criteria of $\geq 1 \mathrm{~mm}$ of ST elevation in 2 contiguous leads or ST depression consistent with posterior infarction, with absence of $Q$ waves in the area of injury.

Coronary angiograms were obtained in 17 of 20 misdiagnosed patients $(85 \%)$ and in 1,316 of 1,367 patients (96\%) with acute infarction. No difference in left ventricular ejection fraction was observed between the 2 groups (acute infarction patients $51 \pm 12 \%$ vs misdiagnosed patients $48 \pm 14 \% ; \mathrm{p}=\mathrm{NS}$ ). In the misdiagnosed group, 8 patients had no coronary artery stenoses $\geq 50 \%$; 3 had 1-vessel disease, 3 had 2-vessel disease, and 3 patients had 3-vessel disease.

Retrospective review of the records of the misdiagnosed group revealed no evidence of cocaine use, alcohol intoxication or other substance abuse in the 20 patients.

Outcomes for patients: Patients with acute infarction in this study had complication rates of $6 \%$ for death, $1.5 \%$ for nonhemorrhagic stroke, $1 \%$ for intracranial bleed, $17 \%$ for bleeding needing transfusion of $\geq 2$ units of packed red blood cells, and $2 \%$ for surgical repair of the catheterization site; no patient in the misdiagnosed group (95\% confidence interval 0 to $14 \%$ ) had any of these complications..$^{19}$ No incidences of cardiac tamponade, aortic dissection, complications of central line placement, or other major iatrogenic complications were observed. One patient developed a large hematoma at a peripheral intravenous site, 2 developed transient hematuria after placement of a urethral catheter, and 1 experienced chills with administration of urokinasc.

One patient in the misdiagnosed group with 3-vessel coronary artery disease developed refractory unstable angina and needed urgent coronary bypass surgery. This patient received 3 units of packed red blood cells in the perioperative period. Two other patients in the misdiagnosed group with unstable angina underwent angioplasty procedures without complication. Two additional patients eventually needed elective coronary bypass surgery.

\section{DISCUSSION}

The major findings of this study were as follows: (1) The incidence of misdiagnosis of acute myocardial infarction was quite low when specific historical, clinical and electrocardiographic criteria were used; and (2) the use of clinical and electrocardiographic criteria such as ours may reduce the risk of serious bleeding in patients who are misdiagnosed; no deaths or significant untoward events occurred.

Careful attention to the electrocardiogram is underscored in this study; $55 \%$ of patients (11 of 20) misdiagnosed had a nondiagnostic entry electrocardiogram. Trials using more permissive criteria than those of this study for administering thrombolytic therapy have been completed. In Gruppo Italiano per lo Studio della Streptochinasi nell'Infarcto Miocardico (GISSI), ${ }^{5}$ patients were not excluded if a $\mathrm{Q}$ wave was observed in the area of injury; patients were also enrolled for ST depression in the limb leads. The misdiagnosis rate was $5.8 \%$. The Anglo-Scandinavian Study of Early Thrombolysis (ASSET) enrolled 2,516 patients based on the clinical decision of the physician treating the patient, and the percentage of patients misdiagnosed was $10.5 \% .^{6}$ The Thrombolysis Early in Acute Heart Attack Trial (TEAHAT $)^{10}$ enrolled 352 patients with suspected acute infarction within 165 minutes of chest pain without requiring electrocardiographic criteria; a misdiagnosis rate of $41 \%$ was observed. Thus, in our study with the use of specific electrocardiographic criteria in addition to historical and clinical criteria, a misdiagnosis rate of $1.4 \%$ compares very favorably.

Did this lower incidence of mistaken diagnosis account for the absence of major adverse consequences in patients misdiagnosed for acute myocardial infarction? In ASSET, patients with suspected infarction were given recombinant tissue plasminogen activator; 5 aortic dissections from the cohort of 2,516 patients were recognized in the first 24 hours and were fatal within 48 hours, and 2 dissections were discovered later during the hospital stay. ${ }^{6,20}$ No aortic dissections were observed in our study. This could be due to the more restrictive electrocardiographic changes required. It could also be due to chance alone, with an incidence of aortic dissection in the United States of approximately $0.03 \%$ yearly. ${ }^{21}$ However, patients with aortic dissection may have clinical presentations imitating myocardial infarction, 22 and the more specific criteria may have conferred a diagnostic and survival benefit. Furthermore, in ASSET, among patients in whom a nonischemic chest pain syndrome was finally diagnosed, those treated with thrombolytic therapy had a $9.5 \%$ mortality rate compared with $1.2 \%$ for those treated with placebo. ${ }^{9}$ Thus, the absence of more specific criteria may have contributed to patients with other conditions (e.g., pericarditis and gastrointestinal disease) receiving thrombolytic therapy and having adverse consequences., $93-25$

'I'he small number of patients in the misdiagnosed group limits the ability to demonstrate absence of adverse effects. No major complication in 20 patients has a wide confidence interval $(0$ to $14 \%) .{ }^{19} \mathrm{~A}$ study with a larger number of misdiagnosed patients would give greater power to the analysis of complication rates. For example, at a power of $80 \%$ and alpha of 0.05 , a total of 125 misdiagnosed patients would be needed to detect a $5 \%$ complication rate. The small number of misdiagnosed patients in our cohort weakens the ability to state that patients inappropriately given thrombolytic therapy using our inclusion criteria have no or few adverse outcomes. Studies with larger numbers of misdiagnosed patients will be able to better comment on complication rates, but will also need to be interpreted in regard to the inclusion criteria used (lax vs strict).

An issue in any study assessing misdiagnosed patients given thrombolytic therapy is that the treatment may abort a potential myocardial infarction by achieving clot lysis and reperfusion before myocardial necro- 
sis occurs. In this study, 20 patients had no evidence of acute myocardial infarction based on ventriculogram, cardiac enzymes and evolutionary changes in the electrocardiogram. Of these patients, 9 had underlying coronary artery disease at catheterization. Eight patients had normal coronary arteries or insignificant coronary artery disease. Three patients in the misdiagnosed group did not have catheterization. Thus 20 of 1,387 patients could have lysed thrombus before progression to infarction. All patients in this group survived, but the numbers are too small to make conclusions regarding the benefit of thrombolytic therapy to patients with unstable angina. No large, randomized, controlled trial has been reported to evaluate whether thrombolytic therapy is beneficial for patients with unstable angina. ${ }^{26}$

The role of thrombolytic therapy in the treatment of patients with acule myocardial infarction continues to develop. The criteria used for inclusion in this study may prove to be too restrictive. Cragg et a ${ }^{27}$ reviewed 1,471 patients with acute myocardial infarction who presented to a large, community-based hospital; only $230(16 \%)$ were eligible for thrombolytic therapy under protocol criteria similar to those in our study. Lee et al ${ }^{11}$ evaluated 7,734 patients presenting to the emergency wards of 3 university and 4 community hospitals; 1,118 were ultimately shown to have acute infarction. Of these patients, $41 \%$ would have fulfilled electrocardiographic criteria similar to those used in our study. If other criteria were used (chest pain $<6$ hours and bleeding risk factors) this percentage would decrease to $25 \% .25$ Many patients with acute infarction who do not fulfill the criteria of our study may benefit from thrombolytic therapy. The results from ISIS- $2^{4}$ suggest that infarcting patients may benefit from treatment with thrombolytic therapy up to 24 hours after the onset of chest pain. ISIS-2 also suggests that patients aged $>75$ years may have substantial benefit from thrombolytic therapy, with mortality in this group reduced from 13 to $9 \% .4,28$ In ASSET, trends toward survival benefit were observed in all groups, including those who had normal electrocardiograms. ${ }^{6}$ The results from on-going clinical trials, as well as future developments in biochemical tests and noninvasive modalities for early diagnosis, should better clarify which patients to treat with thrombolytic therapy in the setting of acute myocardial infarction. ${ }^{28-30}$

\section{REFERENCES}

1. Braunwald $E$. Myocardial reperfusion, limitation of infarct size, reduction of left ventricular dysfunction, and inproved survival-should the paradigm be expanded? Circulation 1989:79:441-444.

2. O'Neill WW, Topol EJ, Pitt B. Reperfusion therapy of acute myocardial infarction. Prog Cardiovasc Dis 1988:30:235-266.

3. Chesebro JH, Holmes DR, Mock MB, Gersh BJ, Fuster V. Thrombolysis in acute myocardial infarction. Cardiol Clin 1988;6:119-137.

4. ISIS-2 Collaborative Group. Randomised trial of intravenous streptokinase, oral aspirin, both, or neither among 17,187 cases of suspected acute myocardial infarction: ISIS-2. Lancet 1988;II:349-360.

5. Gruppo Italiano per lo Studio della Streptochinasi nell'Infarcto Miocardico (GISSI). Effectiveness of intravenous thrombolytic treatment in acute myocardial infarction. Lancet 1986;: $: 397-401$

6. Wilcox RG, Olsson CG, Skene AM, von der Lippe G, Jensen G, Hampton JR. Trial of tissue plasminogen activator for mortality reduction in acute myocardial infarction (ASSET). Lancet 1988;II:525-530.

7. AIMS Trial Study Group. Effect of intravenous APSAC on mortality after acute myocardial infarction: preliminary report of a placebo-controlled clinical trial. Lancet 1988:I:545-549.

8. Califf RM, Topol EJ, George BS, Boswick JM, Abbottsmith CW, Sigmon KN, Candela R, Masek R, Dereiakes D, O'Neill WW, Stack RS, Stump D. Hemorrhagic complications associated with the use of intravenous tissue plasminogen activator in treatment of acute myocardial infarction. Am J Med 1988;85:353-359.

9. Blankenship JC, Almquist AK. Cardiovascular complications of thrombolytic therapy in patients with a mistaken diagnosis of acute myocardial infarction. $J \mathrm{Am}$ Coll Cardiol 1989;14:1579-1582.

10. TEAHAT study group. Very early thrombolytic therapy in suspected acute myocardial infarction. Am J Cardinl 1990;65:401-407.

11. Lee TH, Weisberg MC, Brand DA, Rouan GW, Goldman L. Candidates for thrombolysis among emergency room patients with acute chest pain: potential trueand false-positive rates. Ann Intern Med 1989;110:957-962.

12. Topol EJ, Califf RM, George BS, Dereiakes DJ, Abbottsmith CW, Candela RI, Lee KL, Pitt B, Stack RS, O'Neill WW. A randomized trial of immediate versus delayed elective angioplasty after intravenous tissue plasminogen activator in acute myocardial infarction. $N$ Engl J Med 1987;317:581-588.

13. Topol EJ, Califf RM, George BS, Kereiakes DJ, Rothbaum D, Candela RJ, Abbottsmith CW, Pinkerton C, Stump DC, Collen D, Lee KL, Pitt B, Kline EM Boswick JM, O'Neill WW, Stack RS. Coronary arterial thrombolysis with combined infusion of recombinant tissue-type plasminogen activator and urokinase in patients with acute myocardial infarction. Circulation 1988;77:1100-1107.

14. Topol EJ, George RS, Kereiakes DJ, Stump DC, Candela RJ, Abbottsmith CW, Aronson L, Pickel A. Boswick JM, Lee KL. Ellis SG, Califf RM. A randomized controlled trial of intravenous tissue plasminogen activator and early intravenous heparin in acute myocardial infarction. Circulation 1989;79:281-286.

15. Wall TC, Strickland J, Masoud J, Tse A, Pasi D, Zawodniak M, Anderson J, Hoekstra J, Mantell S, Sigmon K, Stack RS, Phillips HR, Califf RM. Thrombolytic therapy on the homefront; intravenous urokinase in community hospitals. $N C$ Med J 1989;50:363-366

16. Califf RM, Topol EJ, Stack RS, Ellis SG, George BS, Kereiakes DJ, Samaha JK, Worley SJ, Anderson JL, Harrelson-Woodlief L. Evaluation of combination thronbolytic therapy and timing of cardiac catheterizalion in acute myocardial infarction. Results of Thrombolysis and Angioplasty in Myocardial Infaretion-phase 5 randomized trial. TAMI Study Group. Circulation 1991;83:1543-1556.

17. Sandler H, Dodge HT. The use of single plane angiocardiograms for the calculation of left ventricular volume in man. Am Heart $J$ 1968;75:325-334.

18. Mancini GBJ, Simon SB, McGillem MJ, LeFree MT, Friedman HZ, Vogel RA. Automated quantitative coronary arteriography: morphologic and physiologic validation in vivo of a rapid digital angiographic method. Circulation $1987 ; 75: 452-460$

19. Hanley JA, Lippman-Hand A. If nothing goes wrong, is everything all right? Interpreting zero numerators. JAMA 1983;249:1743-1745.

20. Peter RH. Thrombolysis II: lax diagnostic criteria can have deadly consequences. $J$ Crit lliness $1990 ; 5: 418-421$.

21. Sorenson HR, Olsen $H$. Ruptured and dissecting aneurysms of the aorta. Acta Chir Scand 1964;128:644

22. Satler LF, Levine $S$, Kent KM. Aortic dissection masquerading as acute myocardial infaretion: implication for thrombolytic therapy without cardiac cathetcrization. Am J Cardiol 1984;54:1134-1135.

23. Tilley WS, Harston WE. Inadvertent administration of streptokinase to patients with pericarditis. Am I Med 1986:81:541-544

24. White HJ, Williams DO. Selection of patients for thrombolytic therapy. In: Califf RM, Mark DB, Wagner GS, eds. Acute Coronary Care in the Thrombolyt ic Era. London: Yearbook Medical, 1988:173-183.

25. Tate DA, Dehmer GJ. New challenges for thrombolytic therapy. Ann Intern Med 1989;110:953-954.

26. Williams DO, Topol EJ, Califf RM, Roberts R, Mancini J, Joelson JM, Ellis $\mathrm{SG}$, Kleiman NS. Intravenous recombinant tissue-type plasminogen activator in patients with unstable angina pectoris-results of a placebo-controlled, randomized trial. Circulation 1990:82:376-383.

27. Cragg DR, Friedman IZ, Bonema JD, Jaiyesimi IA, Ramos RG, Timmis GC, O'Neill WW, Schreiber TL. Outcome of patients with acute myocardial infarction who are ineligible for thrombolytic therapy. Ann Intern Med 1991;115:173-177.

28. Braunwald E. Optimizing thrombolytic therapy of acute myocardial infarction. Circulation 1990:82:1510-1513

29. Ohman EM, Sigmon KN, Califf RM. Is diagnostic certainty essential for the use of thrombolytic therapy during myocardial infarction in the 1990s? Circulation 1990;1073-1075.

30. Peels CH, Visser CA, Kupper AJF, Visser FC, Roos JP. Usefulness of twodimensional echocardiography for immediate detection of myocardial ischemia in the emergency room. Am J Cardiol 1990;65:687-691. 